\title{
Attitude and Response of First-Year Medical Students Toward Cadaver, Dissection, and Subject of Anatomy: A Qualitative Study
}

\author{
${ }^{1}$ Monika Lalit, ${ }^{2}$ Anupama Mahajan, ${ }^{3}$ Anterpreet K Arora, ${ }^{4}$ Sanjay Piplani
}

\begin{abstract}
Background: The first-year medical students go through the anatomy curriculum which involves extensive anatomy teaching by dissection and experience a variety of emotional reactions and mixed feelings when they encounter the human cadavers for the first time. Therefore, the present study was designed to explore the attitude and views of first-year medical students toward cadaver dissection.
\end{abstract}

Materials and methods: This observational study was performed on newly admitted 150 first-year medical students, at the Department of Anatomy at a tertiary care teaching hospital and medical college in Amritsar, Punjab. A performa was designed with a structured questionnaire having 22 items requiring "yes, no, or undecided" responses and 6 items with Likert-type questions ranging from strongly agree to strongly disagree. One hundred thirty-eight students participated in the study and answered the questionnaires. The data were compiled and analyzed.

Result: The impact of cadaveric dissection on the students that sway on routine activity was observed like nausea $(20.28 \%)$, dizziness $(2.89 \%)$, weakness $(3.62 \%)$, fear $(9.42 \%)$, tremor $(1.45 \%)$, sweating $(4.35 \%)$, restlessness $(10.14 \%)$, lack of concentration (13.77\%), sleep disturbance (3.62\%), etc. The results showed that $94.2 \%$ of the students found their first visit to the dissection room exciting. About $9.42 \%$ of the students were upset at the beginning of the dissection. About $84.78 \%$ of the students did not show any anxiety and stress immediately before and during dissection. About $47.83 \%$ of the students were found mentally prepared for the dissection and $86.96 \%$ agreed that dissection enhanced there thinking skills. About $96.37 \%$ of the students agreed that dissection provided the best method for learning anatomy.

Conclusion: Most of the students in the present study reported their first exposure to dissection hall thrilling. It was also inferred that cadaveric dissection for learning anatomy is still considered important and indispensable and cannot be substituted by any other tool and technique.

\footnotetext{
${ }^{1}$ Associate Professor, ${ }^{2}$ Professor and Head, ${ }^{3,4}$ Professor

${ }^{1-3}$ Department of Anatomy, Guru Ram Das Institute of Medical Sciences \& Research, Amritsar, Punjab, India
}

${ }^{4}$ Department of Pathology, Sri Guru Ram Das Institute of Medical Sciences \& Research, Amritsar, Punjab, India

Corresponding Author: Monika Lalit, Associate Professor, Department of Anatomy, Sri Guru Ram Das Institute of Medical Sciences \& Research, Amritsar, Punjab, India, Phone: +91 9814325454, e-mail: monika.lalit@yahoo.com
Keywords: Anatomy education, Attitudes, Cadaver dissection, Psychology reactions.

How to cite this article: Lalit M, Mahajan A, Arora AK, Piplani S. Attitude and Response of First-Year Medical Students Toward Cadaver, Dissection, and Subject of Anatomy: A Qualitative Study. Curr Trends Diagn Treat 2018;2(2):121-129.

\section{Source of support: Nil}

Conflict of interest: None

\section{INTRODUCTION}

Human anatomy is one of the first, most basic, and a major part of the core education necessary for undergraduates and understanding of further medical sciences. The provision of learning gross anatomy provides an emotional as well as intellectual approach to medical education. Cadaver-based anatomical education is a prerequisite for optimal training and is necessary for establishing the primary of the patient, apprehension of the multidimensional body, anatomical variability, learning the basic language of medicine, and touch-mediated perception of the cadaver or the patient. ${ }^{1}$ Cadaver dissection also plays a very important role and acts as a building block that provides essential knowledge required for the duration of the future studies of the MBBS students. It has been the central pillar of anatomy learning since renaissance ${ }^{2}$ and is considered as essential requirements in learning gross anatomy, particularly the three-dimensional aspect of human anatomy. ${ }^{1,3}$ Dissection of a human body during an anatomy course raises questions for the first-year medical student about the invasion of privacy, cadaver sources, dying, and death. ${ }^{1,4}$ The affective and emotional aspects of human dissection are salient ingredients in professional formation and professionalism signifies medical integrity and guarantees correct professional conduct. ${ }^{5}$ First-year medical students normally experience a variety of emotional reactions and mixed feelings, when they encounter human cadavers for the first time. ${ }^{6}$ Distressing aspects of cadaver dissection include the sight and smell of dead bodies, shock at confronting death, desecration and dismemberment, dehumanization, and invasion of privacy. ${ }^{7}$ There are also concerns that the practice of cadaver dissection may remove the fear factor and the urgency to save actual patients, since the medical students become 
accustomed to death and suffering. The anatomists are often the first teachers in the curriculum who need to be aware of ethical problems. So, more attention to be paid to the first encounter of the students with the cadaver and the students should be offered the opportunity to discuss their emotions. ${ }^{8}$

The present study is an assessment of the response of the undergraduate to dissection and anatomy teaching in an attempt to formulate effective aids of anatomy teaching to medical students. So, this study was conducted to assess the attitude, to analyze the psychological and emotional reactions and mixed feelings among first-year medical students on exposure to human cadaver in a dissection hall, and also to explore further insights into these areas in Indian students.

\section{MATERIALS AND METHODS}

\section{Place of Study and Study Population}

The study was carried out at the Department of Anatomy at a tertiary care hospital and medical college in Amritsar, Punjab. One hundred fifty first-year professional MBBS students of 2018 to 2019 academic sessions formed the study population.

\section{Data Collection}

Out of 150 students, 138 medical students participated in the study. The purpose of the study was explained to each student. Informed consent was obtained from the study population before data were collected. The structured questionnaire having four parts was distributed to the students. In the first part, the sociodemographic information like gender, religion, food habits, occupation of parents, etc., is provided (Table 1). The second part of questionnaire provided information on physical and emotional responses of the students like nausea, dizziness, weakness, fear, tremors, sweating, lack of concentration, etc., (Table 2). The students were asked to answer in either "Yes" or "No" option in these two parts. In the third part, a set of 22 questions evaluated the concerns and feelings of students on handling anatomy specimens and cadavers (Table 3). The questionnaire provided information about their first visit to a dissection room, emotional shock, feelings, anxiety and stress upon initial exposure to cadaver, mental preparation before dissection, sympathy and respect for the cadaver, prior experience with a dead body before dissection, ethical considerations in dissection and the possible alternatives for replacing cadaver dissection by plastic models, and computer-assisted training program and its importance and indispensability. For each question, the student had to choose one of the three possible responses: "yes," "no," and "undecided." The fourth part which is a 5-statement section on student's opinions on cadaver dissection and human anatomy had five alternatives where students were supposed to tick ranging from strongly agree to strongly disagree (Table 4).

\section{Data Analysis}

Various emotional reactions and views among participated students were collected. The data thus obtained were analyzed using the computer program SPSS version 17.1. Descriptive statistics like means and frequencies of the replies was determined for each item of the questionnaire. The results were discussed in the light of available literatures (Table 5).

\section{RESULTS AND DISCUSSION}

Out of total 150 students, 138 (92\%) students participated in the study. Of the 138 students, 68 (49\%) students were

Table 1: Sociodemographic profile of the students in this study (2019)

\begin{tabular}{llllr}
\hline \multirow{2}{*}{ S. no. } & Characteristic & & $\begin{array}{c}\text { Number of students } \\
(n=138)\end{array}$ & Percentage \\
\hline 1 & Gender & Male & 68 & 49 \\
& & Female & 70 & 51 \\
2 & Religion & Hindu & 86 & 62.31 \\
& & Sikh & 44 & 31.38 \\
& & Christian & 2 & 1.44 \\
& & Muslim & 2 & 1.44 \\
3 & Food habit & Others & 4 & 2.89 \\
& & Vegetarian & 62 & 44.92 \\
4 & Occupation of father & Nonvegetarian & 76 & 55.07 \\
& & Employed & 133 & 96.37 \\
5 & Occupation of mother & Unemployed & 5 & 3.62 \\
& & Employed & 86 & 62.31 \\
6 & Whether exposed to animal & Unemployed & 52 & 37.68 \\
& dissection in school & Yes & 7 & 5.07 \\
& & No & 131 & 94.92 \\
\hline
\end{tabular}


First-Year Medical Students Toward Cadaver, Dissection, and Subject of Anatomy

\begin{tabular}{|c|c|c|c|c|c|}
\hline S. no. & Particulars of questions & $\begin{array}{l}\text { Number of students } \\
\text { with response "NO" }\end{array}$ & Percentage & $\begin{array}{l}\text { Number of students with } \\
\text { response "YES" }\end{array}$ & Percentage \\
\hline 1 & Nausea & 110 & 79.71 & 38 & 20.28 \\
\hline 2 & Dizziness & 134 & 97.10 & 4 & 2.89 \\
\hline 3 & Weakness & 133 & 96.37 & 5 & 3.62 \\
\hline 4 & Fear & 125 & 90.57 & 13 & 9.42 \\
\hline 5 & Tremor & 136 & 98.55 & 2 & 1.45 \\
\hline 6 & Sweating & 132 & 95.65 & 6 & 4.35 \\
\hline 7 & Difficulty in breathing & 113 & 81.88 & 25 & 18.11 \\
\hline 8 & Restlessness & 124 & 89.55 & 14 & 10.14 \\
\hline 9 & Lack of concentration & 119 & 86.23 & 19 & 13.77 \\
\hline 10 & $\begin{array}{l}\text { Difficulty in consuming } \\
\text { non-vegetarian food }\end{array}$ & 129 & 93.47 & 9 & 6.52 \\
\hline 11 & Sleep disturbance & 133 & 96.37 & 5 & 3.62 \\
\hline 12 & No feeling & 84 & 60.86 & 54 & 39.13 \\
\hline
\end{tabular}

males and $70(51 \%)$ students were females. Their sociodemographic profile, physical and emotional responses, and responses on attitude before and on encounter with cadaver in dissection hall, toward dissection, and subject of anatomy are summarized in Tables 1 to 3.

It is an established fact that students learn anatomy from the dead. First-year medical students normally experience varying responses on encounter with cadaver in the dissection hall, toward dissection, and subject of anatomy. An analysis of the questionnaire from the present study revealed favorable outlook to cadaver dissection and its indispensability in anatomy learning. These findings demonstrate that medical students are eager to learn from the cadaver, their "first patient." This is despite mounting concerns over the traumatic effects of dissection and its implications to subsequent education and practice. ${ }^{9}$

As can be seen from Table 5 that 130 (94.2\%) students found their first visit to the dissection room exciting. This is not in agreement with previous studies done by Izunya et al., ${ }^{10}$ Agnihotri et al., ${ }^{11}$ Karau et al., ${ }^{15}$ Saha et al., ${ }^{16}$ and no mention about their visit in the dissection-hall by Naz et al., ${ }^{12}$ Dubhashi et al., ${ }^{13}$ and Oyeyipo et al., ${ }^{14}$ whereas Rajkumari et al. ${ }^{2}$ revealed that $85 \%$ of the respondents found their visit exciting. Forty-eight (34.78\%) students experienced emotional shock at initial exposure to the cadaver, while $13(9.42 \%)$ of the respondents were upset at the beginning of dissection, this is in concordance with the reports by Karau et al. ${ }^{15}$ but contradicts the findings by Nnodim et al. ${ }^{17}$ who reported that over threequarters of the students were upset at the beginning of dissection. We found that $27(19.56 \%)$ students were apprehensive about handling the cadavers directly. This is lower than that reported by Rajkumari et al., ${ }^{2}$ Izunya et al., ${ }^{10}$ Agnihotri et al., ${ }^{11}$ and Oyeyipo et al. ${ }^{14}$ which may be due to poor prior knowledge on what anatomy and cadaver dissection entails and in concordance with
Karau et al. and Saha et al., ${ }^{15,16}$ while 21 (15.21\%) students experienced considerable anxiety and stress immediately before and during dissection. This is not in agreement with Rajkumari et al., ${ }^{2}$ Arráez-Aybar, ${ }^{3}$ Agnihotri et al., ${ }^{11}$ Naz et al., ${ }^{12}$ Dubhashi et al., ${ }^{13}$ Karau et al., ${ }^{15}$ and Saha et al. ${ }^{16}$ A majority of our study respondents 66 (47.83\%) reported adequate mental preparation for dissection which concurred with the findings of Karau et al. ${ }^{15}$ This indicates the seriousness and attention they give to the learning of anatomy and may possibly explain the relatively lower levels of anxiety and apprehension on initial exposure to cadavers. It has been reported that sometimes the urge and strong interest in medicine as a career motivates students and lowers levels of mental stress while increasing their preparedness (Rajkumari et al.). ${ }^{2}$ Fifty-eight $(42.03 \%)$ students had prior experience with a dead body. Parker ${ }^{18}$ reported that students with prior exposure with a dead body will be better equipped to deal with issues surrounding death and are more aware of medical uncertainties. One hundred sixteen (80.06\%) students agreed that cadavers were once living humans like them, while 132 (95.66\%) had sympathy and respect for them. This is higher than the studies done by previous authors. There is a need to emphasize the sanctity of the cadaver as a human specimen, so as to inculcate into students' carefulness and empathy, which is important in the subsequent medical practice. One hundred thirtyeight $(100 \%)$ respondents realized that the cadaveric oath pledge or recitation has a role in developing empathy for cadaver as silent teachers and $136(98.55 \%)$ students had a sense of gratitude to people who donated their dead bodies for them to learn which is in concordance with the work done by Saha et al. ${ }^{16}$ For $113(81.88 \%)$ students, the cadaver dissection is ethically acceptable which is not in agreement with the previous findings. One hundred fourteen $(82.61 \%)$ students liked to hold the bones which support the findings of Saha et al. ${ }^{16}$ 
Monika Lalit et al.

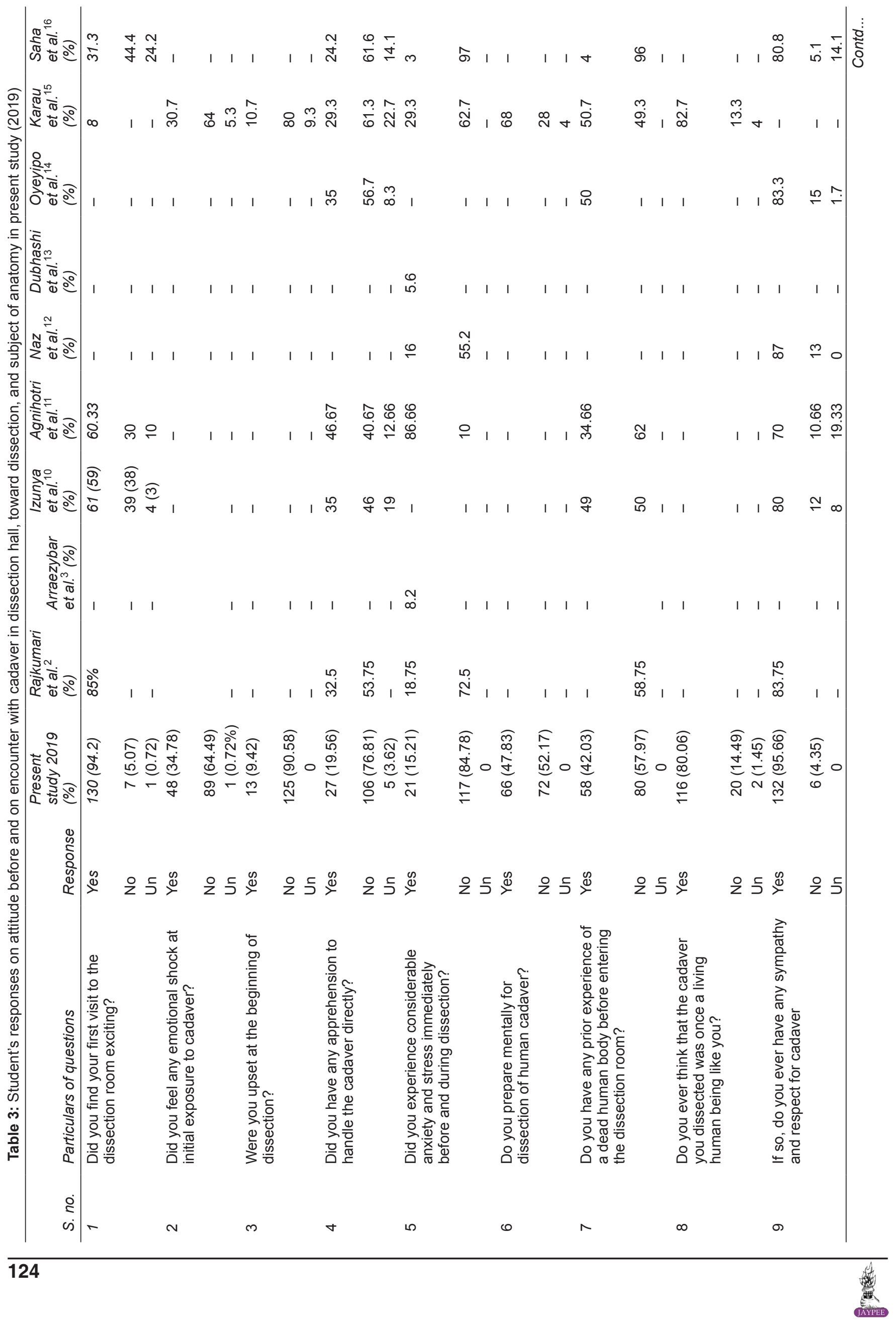




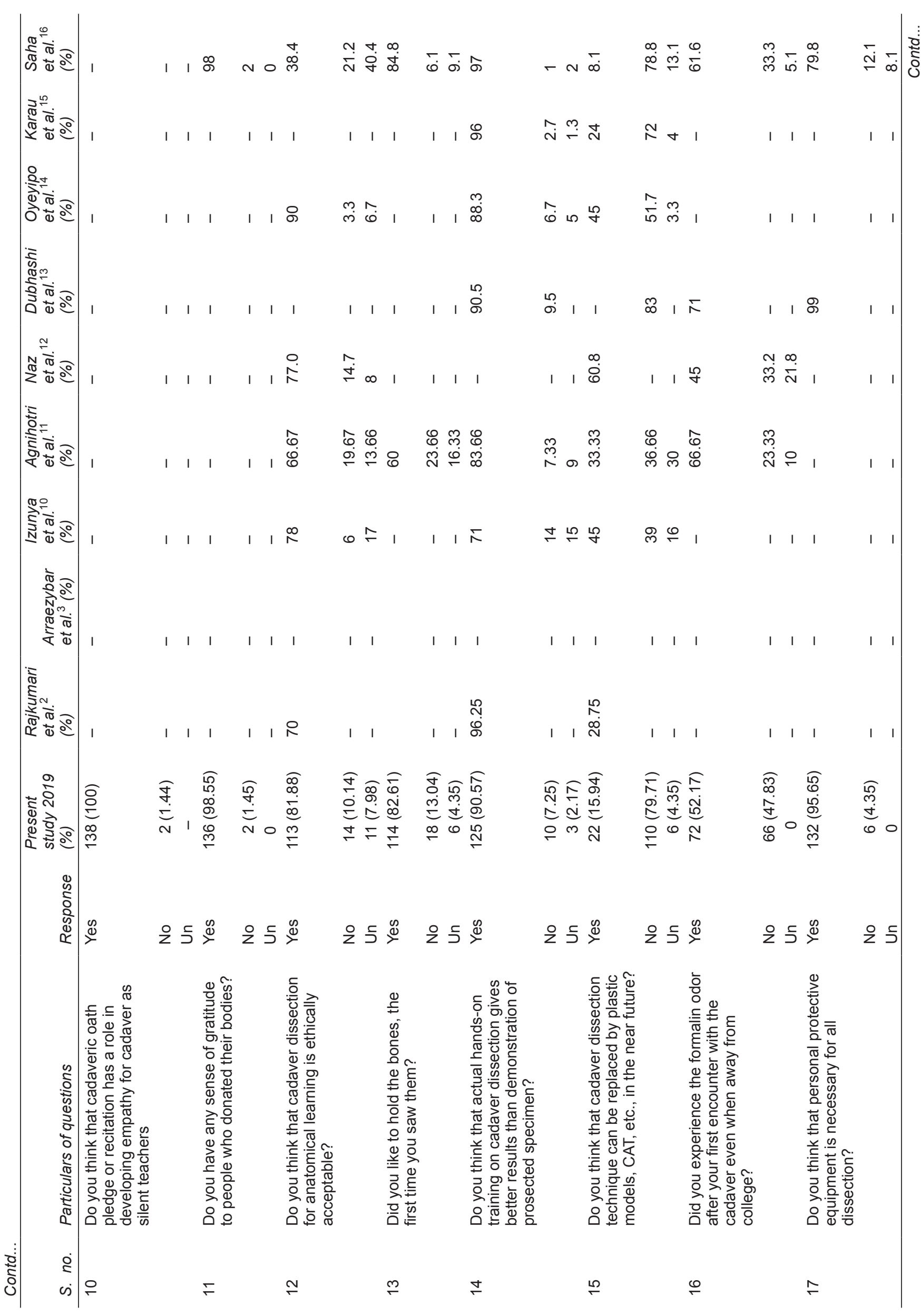




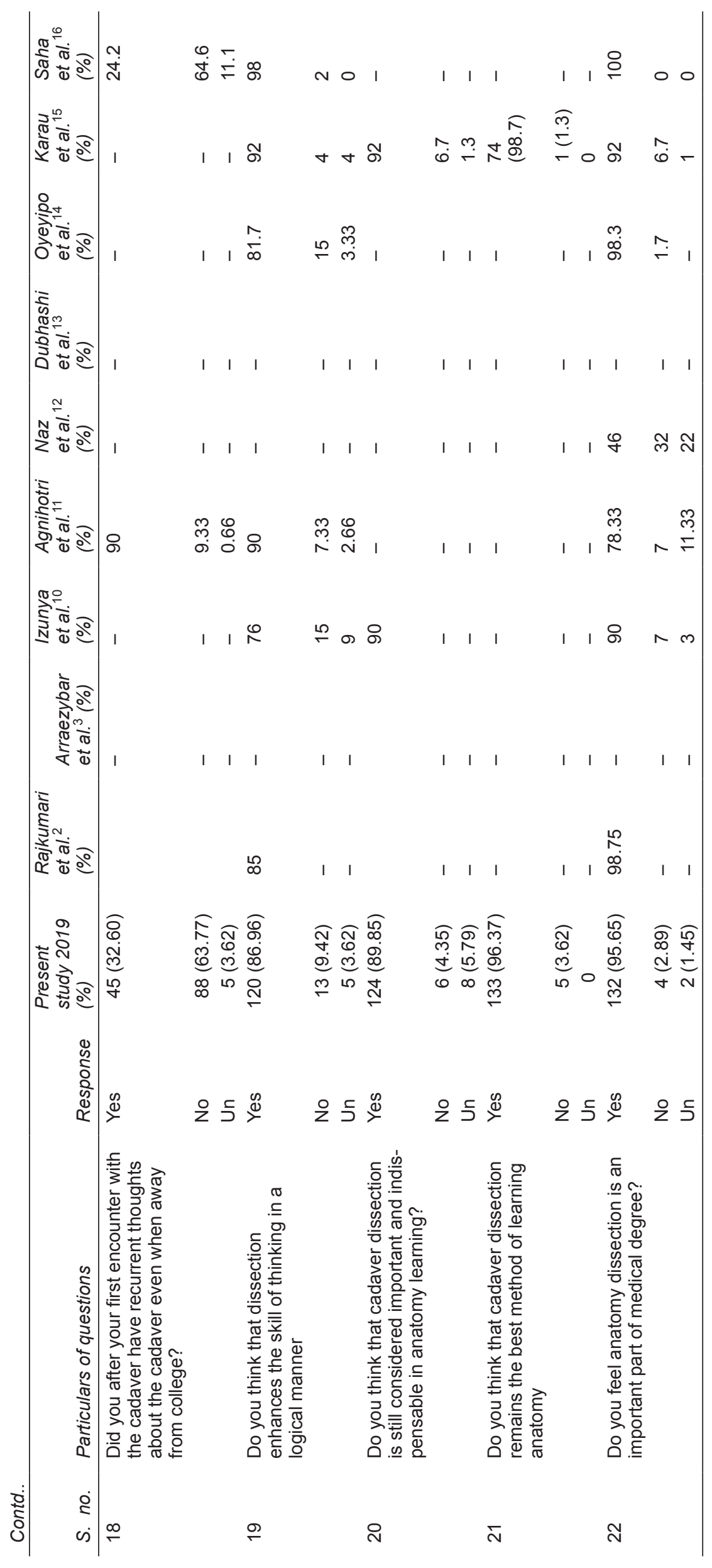


Table 4: Students' opinions on cadaver dissection and human anatomy

\begin{tabular}{|c|c|c|c|c|c|c|}
\hline & & $\begin{array}{l}\text { Strongly } \\
\text { agree (\%) }\end{array}$ & Agree (\%) & Neutral (\%) & Disagree (\%) & $\begin{array}{l}\text { Strongly } \\
\text { disagree (\%) }\end{array}$ \\
\hline S. no. & Particulars of questions & 1 & 2 & 3 & 4 & 5 \\
\hline 1 & I dislike anatomy as a subject & $8(5.79)$ & $16(11.59)$ & $43(31.16)$ & $47(34.05)$ & $24(17.39)$ \\
\hline 2 & I find the dissection experience distasteful & $5(3.62)$ & $5(3.62)$ & $37(26.81)$ & $66(47.83)$ & $25(18.11)$ \\
\hline 3 & I would choose anatomy as a career & $1(0.72)$ & $11(7.97)$ & $48(34.78)$ & $38(27.54)$ & $40(28.98)$ \\
\hline 4 & $\begin{array}{l}\text { I would recommend anatomy as a career } \\
\text { to my peers }\end{array}$ & $1(0.72)$ & $16(11.59)$ & $62(44.92)$ & $32(23.18)$ & $27(19.56)$ \\
\hline 5 & $\begin{array}{l}\text { I would not choose a career which involves } \\
\text { anatomy }\end{array}$ & $5(3.62)$ & $16(11.59)$ & $48(34.78)$ & $51(36.95)$ & $18(13.04)$ \\
\hline
\end{tabular}

Table 5: Comparison of student's responses on attitude before and on encounter with cadaver in dissection hall, toward dissection, and subject of anatomy

\begin{tabular}{|c|c|c|c|c|}
\hline S. no. & Particulars of questions & $\begin{array}{l}\text { Number of } \\
\text { "Yes" (\%) }\end{array}$ & $\begin{array}{l}\text { Number of } \\
\text { "No" (\%) }\end{array}$ & $\begin{array}{l}\text { Number of } \\
\text { "Undecided" (\%) }\end{array}$ \\
\hline 1 & Did you find your first visit to the dissection room exciting? & $130(94.2)$ & $7(5.07)$ & $1(0.72)$ \\
\hline 2 & Did you feel any emotional shock at initial exposure to cadaver? & $48(34.78)$ & $89(64.49)$ & $1(0.72)$ \\
\hline 3 & Were you upset at the beginning of dissection? & $13(9.42)$ & $125(90.58)$ & 0 \\
\hline 4 & Did you have any apprehension to handle the cadaver directly? & $27(19.56)$ & $106(76.81)$ & $5(3.62)$ \\
\hline 5 & $\begin{array}{l}\text { Did you experience considerable anxiety and stress immediately before } \\
\text { and during dissection? }\end{array}$ & $21(15.21)$ & $117(84.78)$ & 0 \\
\hline 6 & Do you prepare mentally for dissection of human cadaver? & $66(47.83)$ & $72(52.17)$ & 0 \\
\hline 7 & $\begin{array}{l}\text { Do you have any prior experience of a dead human body before } \\
\text { entering the dissection room? }\end{array}$ & $58(42.03)$ & $80(57.97)$ & 0 \\
\hline 8 & $\begin{array}{l}\text { Do you ever think that the cadaver you dissected was once a living } \\
\text { human being like you? }\end{array}$ & $116(80.06)$ & $20(14.49)$ & $2(1.45)$ \\
\hline 9 & If so, do you ever have any sympathy and respect for cadaver & $132(95.66)$ & $6(4.35)$ & 0 \\
\hline 10 & $\begin{array}{l}\text { Do you think that cadaveric oath pledge or recitation has a role in } \\
\text { developing empathy for cadaver as silent teachers }\end{array}$ & $138(100)$ & 0 & 0 \\
\hline 11 & $\begin{array}{l}\text { Do you have any sense of gratitude to people who donated their } \\
\text { bodies? }\end{array}$ & $136(98.55)$ & $2(1.45)$ & 0 \\
\hline 12 & $\begin{array}{l}\text { Do you think that cadaver dissection for anatomical learning is ethically } \\
\text { acceptable? }\end{array}$ & $113(81.88)$ & $14(10.14)$ & $11(7.98)$ \\
\hline 13 & Did you like to hold the bones, the first time you saw them? & $114(82.61)$ & $18(13.04)$ & $6(4.35)$ \\
\hline 14 & $\begin{array}{l}\text { Do you think that actual hands-on training on cadaver dissection gives } \\
\text { better results than demonstration of prosected specimen? }\end{array}$ & $125(90.57)$ & $10(7.25)$ & $3(2.17)$ \\
\hline 15 & $\begin{array}{l}\text { Do you think that cadaver dissection technique can be replaced by } \\
\text { plastic models, CAT, etc., in the near future? }\end{array}$ & $22(15.94)$ & $110(79.71)$ & $6(4.35)$ \\
\hline 16 & $\begin{array}{l}\text { Did you experience the formalin odor after your first encounter with the } \\
\text { cadaver even when away from college? }\end{array}$ & $72(52.17)$ & $66(47.83)$ & 0 \\
\hline 17 & $\begin{array}{l}\text { Do you think that personal protective equipment is necessary for all } \\
\text { dissection? }\end{array}$ & $132(95.65)$ & $6(4.35)$ & 0 \\
\hline 18 & $\begin{array}{l}\text { Did you after your first encounter with the cadaver have recurrent } \\
\text { thoughts about the cadaver even when away from college? }\end{array}$ & $45(32.60)$ & $88(63.77)$ & $5(3.62)$ \\
\hline 19 & $\begin{array}{l}\text { Do you think that dissection enhances the skill of thinking in a logical } \\
\text { manner }\end{array}$ & $120(86.96)$ & $13(9.42)$ & $5(3.62)$ \\
\hline 20 & $\begin{array}{l}\text { Do you think that cadaver dissection is still considered important and } \\
\text { indispensable in anatomy learning? }\end{array}$ & $124(89.85)$ & $6(4.35)$ & $8(5.79)$ \\
\hline 21 & $\begin{array}{l}\text { Do you think that cadaver dissection remains the best method of } \\
\text { learning anatomy }\end{array}$ & $133(96.37)$ & $5(3.62)$ & 0 \\
\hline 22 & Do you feel anatomy dissection is an important part of medical degree? & $132(95.65)$ & $4(2.89)$ & $2(1.45)$ \\
\hline
\end{tabular}

Furthermore, a majority of the students 125 (90.57\%) agreed that actual hands-on training on cadaver dissection gave better results than demonstration of prosected specimen, as it greatly enhances the understanding of the objectives of the course. Only $22(15.94 \%)$ students in the present study would prefer replacement of cadaver dissection with plastic models or computer-assisted programs. This finding is lower than the findings of Rajkumari et al., ${ }^{2}$
Izunya et al., ${ }^{10}$ Agnihotri et al., ${ }^{11}$ Naz et al., ${ }^{12}$ Oyeyipoi, ${ }^{14}$ and Karau et al. ${ }^{15}$ but at variance from Saha et al. ${ }^{16}$ against the use of cadaveric material in anatomy teaching. Parker ${ }^{18}$ reported that cadaver dissection confers better three-dimensional appreciation of human anatomy as opposed to plastic models. As depicted from the comparative Table 5 that about 72 (52.17\%) students experienced the formalin odor even when they are away from the 
college. One hundred thirty-two (95.65\%) students were in opinion that personal protective equipment is necessary for all dissection. Forty-five $(32.60 \%)$ students had recurrent thoughts about the cadaver even when they are away from college after their first encounter with the cadaver. One hundred twenty $(86.96 \%)$ students also mentioned that dissection enhanced their skill of thinking in a logical manner. This finding is consistent with the studies conducted by Rajkumari et al., ${ }^{2}$ Izunya et al., ${ }^{10}$ Agnihotri et al., ${ }^{11}$ Oyeyipo, ${ }^{14}$ Karau et al., ${ }^{15}$ and Saha et al. ${ }^{16}$ An analysis of the questionnaire also showed that a vast majority of the students 124 (89.85) considered cadaver dissection as important and indispensable in the study of human anatomy. On the preferred method of learning anatomy, it was observed that $133(96.37 \%)$ respondents agreed that dissection remains the best method of learning anatomy and this is consistent with the view held by many anatomists, although there is little hard evidence for this assertion. ${ }^{19}$ One hundred thirty-two $(95.65 \%)$ students also responded that anatomy dissection is an important part of medical degree.

Table 4 depicts the opinion of respondents on cadaver dissection and human anatomy and we found favorable opinions in the term like a majority of $71(34.05 \%+$ $17.39 \%)$ students disagreeing to the statement that they dislike anatomy, while $43(31.16 \%)$ students being neutral. Ninety-one $(47.83 \%+18.11 \%)$ students found the dissection experience tasteful.

This is in agreement with the previous findings of Anand et al. ${ }^{20}$ that medical students generally like anatomy as a subject. However, about $48(34.78 \%)$ students are neutral on choosing anatomy as a career, while one $(0.72 \%)$ and $11(7.97 \%)$ students strongly agree and agree, respectively, that they would choose anatomy as a career. Only $1(0.72 \%)$ and $16(11.59 \%)$ students would recommend anatomy as a career to their peers, while $62(44.92 \%)$ students being neutral. Five (3.62\%) and 16 $(11.59 \%)$ students would also pursue a career that involves anatomy.

It has been ascertained that the manual skills learnt in the dissection room are essential in almost every branch of the medical profession. ${ }^{21}$ Moreover, dissection has been considered as an essential requirement in learning gross anatomy particularly the three-dimensional aspect of human anatomy ${ }^{22}$ and has remained the universally recognizable step in becoming a doctor, ${ }^{23}$ which puts undergraduates at the sharp end of medical education. ${ }^{24}$

\section{CONCLUSION}

Our study showed that most of the first-year medical students reported their first exposure thrilling to the cadaver and the dissection hall. It was also inferred that cadaveric dissection for learning anatomy is still considered important and indispensable and cannot be substituted by any other tool and technique. The medical students also appreciated the usefulness of anatomy as a subject but very few are willing to pursue it.

\section{REFERENCES}

1. Bertman SL, Marks Jr SC. Humanities in medical education: rationale and resources for the dissection laboratory. Med Educ 1985;19(5):374-381.

2. Rajkumari A, Das BK, Sangma GTN, et al. Attitude and views of first year medical students towards cadaver dissection in anatomy learning. Calicut Med J 2008;6:550-554.

3. Arráez-Aybar LA. Dissection as a modulator of emotional attitudes and reactions of future health professionals. Med Educ 2008;42:563-571. doi: 10.1111/j.1365-2923.2008.03079.x.

4. Cahill KC, Ettarh RR. Student attitudes to whole body donation are influenced by dissection. Anat Sci Educ 2008;1(5):212216. doi: 10.1002 /ase.42.

5. Warner JH, Rizzolo LJ. Anatomical instruction and training for professionalism from the 19th to the 21st centuries. Clin Anat 1995;19(5):403-414.

6. Cahill KC, Ettarh RR. Attitudes to anatomy dissection in an Irish medical school. Clin Anat 2009;22(3):386-391. doi: 10.1002/ca.20777.

7. Hafferty FW. Cadaver stories and the emotional socialization of medical students. J Health Soc Behav 1998;29:344-356.

8. Mc Garvey MA, Farrel T, Conroy RM, et al. Dissection: a positive experience. Clin Anat 2001;14(3):227-230. doi: 10.1002/ ca.1037.

9. Charlton R, Dovey SM, Jones DG, et al. Effects of cadaver dissection on the attitudes of medical students. Med Educ 1994;28:290-295.

10. Izunya AM, Oaikhena GA, Nwaopara AO. Attitudes to cadaver dissection in a Nigerian Medical School. Asian J Med Sci 2010;2(3):89-94.

11. Agnihotri G, Sagoo MG. Reactions of first year Indian medical students to the dissection hall experience. NJIRM 2010;1(4):4-9.

12. Naz S, Nazir G, Iram S, et al. Perceptions of cadaveric dissection in anatomy teaching. J Ayub Med Coll Abbottabad 2011;23(3):145-148.

13. Dubhashi S, Dubhashi U, Singh A, et al. Medical students react to cadaveric dissections. Recent Res Sci Technol 2011;3(1):135-138.

14. Oyeyipo IP, Falana BA. Attitude of preclinical students to cadaver dissection in a South West Nigerian Medical School. Int J Trop Med 2012;7(1):1-5.

15. Karau PB, Wamachi A, Ndede K, et al. Perception to cadaver dissection and views on anatomy as a subject between two pioneer cohorts in a Kenyan medical school. Anat J Afr 2014;3(2):318-323.

16. Saha N, Chaudhuri S, Matum SM. Attitude of first year medical students in dissection hall. J Dent Med Sci 2015;14(5): 74-78.

17. Nnodim JO. Preclinical student reactions to dissection, death, and dying. Clin Anat 1996;9(3):175-182. doi: 10.1002/ (SICI)1098-2353(1996)9:3<175::AID-CA9>3.0.CO;2-F. 
18. Parker LM. Anatomical dissection: why are we cutting it out? Dissection in undergraduate teaching. ANZ J Surg 2002;72(12):910-912.

19. Cahill DR, Leonard RJ. The role of computers and dissection in teaching anatomy: a comment (editorial). Clin Anat 1997;10: 140-141. doi: 10.1002/(SICI)1098-2353(1997)10:2<140:: AID-CA13>3.0.CO;2-K.

20. Anand MK, Raibagkar CJ, Ghediya SV, et al. Anatomy as a subject and career option in view of medical students in India. J Anat Soc India 2004;53(1):10-14.
21. Prakash PLV, Rai R, D'Costa S, et al. Cadaver as teachers in medical education: knowledge is the ultimate gift of body donors. Singapore Med J 2007;48(3):186-190.

22. Older J. Anatomy: a must for teaching the next generation. Surg J R Coll Surg Edinb Irel 2004:79-90.

23. Mclachian J, Bradley P, Searle J, et al. Teaching anatomy without cadavers. Med Educ 2004;38:418-424. doi: 10.1046/j.1365-2923.2004.01795.x.

24. Maguire P. Barriers to psychological care of the dying. Br Med J 1985;291:1711-1713. doi: 10.1136/bmj.291.6510.1711. 